\section{BMJ Open \\ Respiratory \\ Research}

\title{
Chronic airflow limitation and its relation to respiratory symptoms among ever-smokers and never-smokers: a cross-sectional study
}

Kjell Toren, ${ }^{1,2}$ Linus Schiöler, ${ }^{1}$ Anne Lindberg, ${ }^{3}$ Anders Andersson, ${ }^{4,5}$ Annelie F Behndig, ${ }^{6}$ Göran Bergström, ${ }^{7}$ Anders Blomberg, ${ }^{3}$ Kenneth Caidahl, ${ }^{8}$ Jan Engvall, ${ }^{9,10}$ Maria Eriksson, ${ }^{11}$ Viktor Hamrefors, ${ }^{12,13}$ Christer Janson, ${ }^{14}$ David Kylhammar, ${ }^{10}$ Eva Lindberg, ${ }^{14}$ Anders Lindén, ${ }^{15}$ Andrei Malinovschi, ${ }^{16}$ Hans Lennart Persson (10 , ${ }^{17}$ Martin Sandelin, ${ }^{18}$ Jonas Eriksson Ström, ${ }^{3}$ Hanan A Tanash, ${ }^{19}$ Jenny Vikgren, ${ }^{20}$ Carl Johan Östgren, ${ }^{21}$ Per Wollmer, ${ }^{22}$ C. Magnus Sköld ${ }^{23,24}$

To cite: Toren $\mathrm{K}$, Schiöler $\mathrm{L}$, Lindberg A, et al. Chronic airflow limitation and its relation to respiratory symptoms among eversmokers and never-smokers: a cross-sectional study. BMJ Open Resp Res 2020;7:e000600. doi:10.1136/ bmjresp-2020-000600

- Additional material is published online only. To view please visit the journal online (http://dx.doi.org/10.1136/ bmjresp-2020-000600).

Received 20 March 2020 Revised 29 June 2020 Accepted 3 July 2020

\section{Check for updates}

(C) Author(s) (or their employer(s)) 2020. Re-use permitted under CC BY-NC. No commercial re-use. See rights and permissions. Published by BMJ.

For numbered affiliations see end of article.

Correspondence to Dr Kjell Toren; kjell.toren@amm.gu.se

\section{ABSTRACT}

Background The diagnosis of chronic obstructive pulmonary disease is based on the presence of persistent respiratory symptoms and chronic airflow limitation (CAL). CAL is based on the ratio of forced expiratory volume in $1 \mathrm{~s}$ to forced vital capacity ( $\mathrm{FEV}_{1}$ :FVC) after bronchodilation, and $\mathrm{FEV}_{1}$ :FVC less than the fifth percentile is often used as a cut-off for CAL. The aim was to investigate if increasing percentiles of $\mathrm{FEV}_{1}$ :FVC were associated with any respiratory symptom (cough with phlegm, dyspnoea or wheezing) in a general population sample of never-smokers and ever-smokers.

Methods In a cross-sectional study comprising 15128 adults (50-64 years), 7120 never-smokers and 8008 ever-smokers completed a respiratory questionnaire and performed $\mathrm{FEV}_{1}$ and $\mathrm{FVC}$ after bronchodilation. We calculated their $z$-scores for FEV using the Global Lung Function Initiative (GLI) reference value, $\mathrm{GLI}_{5}$ and increasing percentiles up to $\mathrm{GLI}_{25}$. We analysed the associations between different strata of percentiles and prevalence of any respiratory symptom using multivariable logistic regression for estimation of $\mathrm{OR}$.

Results Among all subjects, regardless of smoking habits, the odds of any respiratory symptom were elevated up to the $\mathrm{GLI}_{15-20}$ strata. Among never-smokers, the odds of any respiratory symptom were elevated at GLI ${ }_{<5}$ (OR 3.57, 95\% $\mathrm{Cl} 2.43$ to 5.23 ) and at $\mathrm{GLI}_{5-10}(\mathrm{OR} 2.57,95 \% \mathrm{Cl} 1.69$ to 3.91$)$, but not at higher percentiles. Among ever-smokers, the odds of any respiratory symptom were elevated from $\mathrm{GLI}_{<5}(\mathrm{OR}$ $4.64,95 \% \mathrm{Cl} 3.79$ to 5.68$)$ up to $\mathrm{GLI}_{\geq 25}(\mathrm{OR} 1.33,95 \% \mathrm{Cl} 1.00$ to 1.75$)$.

Conclusions The association between percentages of $\mathrm{FEV}_{1}$ :FVC and respiratory symptoms differed depending on smoking history. Our results support a higher percentile cut-off for $\mathrm{FEV}_{1}$ :FVC for never-smokers and, in particular, for ever-smokers.

\section{INTRODUCTION}

Chronic airflow limitation (CAL) is defined by spirometry after bronchodilation, while

\section{Key messages}

Which percentiles of forced expiratory volume in $1 \mathrm{~s}$ to forced vital capacity ratio (FEV :FVC) are associated with increased prevalence of respiratory symptoms in the general population?

$>$ This study demonstrates that a higher percentile ( $\geq 10$ th) of $\mathrm{FEV}_{1}$ :FVC, among never-smokers, but in particular among ever-smokers, is associated with chronic obstructive pulmonary disease-related respiratory symptoms.

- Our results indicate that the prevalence of respiratory symptoms is increased also at percentiles of $\mathrm{FEV}_{1}:$ FVC exceeding the fifth percentile.

diagnosis of chronic obstructive pulmonary disease (COPD) requires respiratory symptoms in addition to CAL. ${ }^{12}$ However, it has been reported that smokers with normal lung function have increased prevalence of respiratory symptoms, as well as a number of comorbidities. ${ }^{34}$ A considerable proportion of individuals with COPD have never smoked, and data are sparse on how this phenotype differs from COPD among smokers in terms of symptoms and mortality. ${ }^{56}$

There is a number of different ways to assess CAL. The Global Initiative for Chronic Obstructive Lung Disease (GOLD) recommends using a fixed ratio of forced expiratory volume in $1 \mathrm{~s}$ to forced vital capacity $\left(\mathrm{FEV}_{1}: \mathrm{FVC}\right)<0.70 .{ }^{1}$ An alternative approach is to estimate the distribution of $\mathrm{FEV}_{1}: \mathrm{FVC}$ in a healthy population, conditional on factors such as age, sex and height. ${ }^{7}$ An $\mathrm{FEV}_{1}:$ FVC less than the fifth percentile of this value is used as a cut-off, referred to as the 'lower limit of 
normal $\left(\mathrm{LLN}_{5}\right)$ '. This approach has been jointly recommended by the American Thoracic Society (ATS) and the European Respiratory Society (ERS). ${ }^{8}$ Several different reference equations have been presented, many of which were estimated using ordinary least squares regression. These have been criticised for the underlying assumption that the values are conditionally normally distributed with constant variance. ${ }^{9}$ Reference equations published by the Global Lung Function Initiative (GLI) were estimated using the lambda-mu-sigma (LMS) method. This method relaxes the assumptions of linearity, constant variance and normality. ${ }^{9} 10$

The assessment of CAL is based on the $\mathrm{FEV}_{1}: \mathrm{FVC}$ ratio with different cut-off limits proposed, and the underlying assumption is that the selected cut-off limit is a marker of increased morbidity and mortality. ${ }^{10}$ However, there is no clear threshold for lung function, and measures of lung function such as $\mathrm{FEV}_{1}: \mathrm{FVC}$ as well as many other clinical measurements are measured along a continuous scale. Hence, the decision limits must be based on both epidemiological data and clinical considerations. One way of establishing decision limits is to evaluate the effect of successively higher percentiles in relation to clinically relevant symptoms. ${ }^{112}$ In a general populationbased study from the USA comprising 3502 individuals, it was shown that among subjects with $\mathrm{FEV}_{1}: \mathrm{FVC}$ below $\mathrm{LLN}_{5}$ based on the LMS method, the adjusted ORs for respiratory symptoms (cough with phlegm, wheezing or dyspnoea) were significantly and almost threefold increased. ${ }^{9}$ However, at higher percentiles, the adjusted
ORs were still increased, but lower and without statistical significance. No separate analyses of never-smokers were presented, even if never-smokers constituted $40 \%$ of the population.

We therefore propose that successively higher (more inclusive) LMS-derived percentiles should be evaluated in relation to clinically relevant symptoms, a composite outcome of cough with phlegm, dyspnoea and wheezing, in large powerful studies, and that these associations should specifically be evaluated in never-smoking populations.

\section{METHODS}

\section{Study population}

Participants were randomly selected from the Swedish population register and invited to participate in the Swedish CArdioPulmonary bioImage Study (SCAPIS), a cross-sectional study of a general population sample. The participation rate was around $50 \% .{ }^{1314}$ The present study was part of an interim analysis and was performed when half of the expected sample had been included. Thus, the current population sample included 15810 adults, 7122 of whom were never-smokers, aged 50-64 years, 7625 men and 8185 women. All subjects answered an extensive respiratory questionnaire comprising the modified Medical Research Council (mMRC) scale, which includes five grades (0-4) for assessing dyspnoea, along with items about smoking habits and socioeconomic status.

Table 1 Descriptive data of the study participants, by sex and smoking

\begin{tabular}{|c|c|c|c|c|c|}
\hline & $\begin{array}{l}\text { All } \\
N=15128\end{array}$ & $\begin{array}{l}\text { Men } \\
n=7268\end{array}$ & $\begin{array}{l}\text { Women } \\
n=7860\end{array}$ & $\begin{array}{l}\text { Ever-smokers } \\
\mathrm{n}=8008\end{array}$ & $\begin{array}{l}\text { Never-smokers } \\
\mathrm{n}=7120\end{array}$ \\
\hline Age (years), mean (SD) & $57.5(4.3)$ & $57.5(4.4)$ & $57.5(4.3)$ & $58.0(4.3)$ & $57.0(4.3)$ \\
\hline BMI $\left(\mathrm{kg} / \mathrm{m}^{2}\right)$, mean (SD) & $26.9(4.4)$ & $27.4(4.0)$ & $26.5(4.8)$ & $27.2(4.5)$ & $26.6(4.4)$ \\
\hline Never-smokers, n (\%) & $7120(47.1)$ & 3587 (49.4) & $3533(44.9)$ & N.A. & $7120(100)$ \\
\hline Ex-smokers, n (\%) & $5769(38.1)$ & $2597(35.7)$ & $3172(40.4)$ & $5769(72.0)$ & N.A. \\
\hline Current smokers, $\mathrm{n}(\%)$ & $2239(14.8)$ & $1084(14.9)$ & 1155 (14.7) & $2239(28.0)$ & N.A. \\
\hline Pack-years, mean (SD) & $16.8(14.0)$ & $18.1(15.0)$ & $15.7(13.0)$ & $16.8(14.0)$ & N.A. \\
\hline Any respiratory symptom*, n (\%) & $1960(13.3)$ & $879(12.5)$ & $1081(14.1)$ & $1301(16.8)$ & $659(9.5)$ \\
\hline Wheeze, n (\%) & $1126(7.6)$ & $530(7.5)$ & $596(7.8)$ & $808(10.4)$ & $318(4.5)$ \\
\hline Dyspnoea, n (\%) & $738(5.0)$ & $244(3.4)$ & $494(6.4)$ & $482(6.2)$ & $256(3.6)$ \\
\hline Cough with phlegm, n (\%) & $734(4.9)$ & $378(5.3)$ & $356(4.6)$ & $490(6.2)$ & $244(3.4)$ \\
\hline Physician-diagnosed asthma, n (\%) & $659(4.4)$ & $278(3.8)$ & $381(4.8)$ & $336(4.2)$ & $323(4.5)$ \\
\hline $\mathrm{FEV}_{1}(\%$ pred $) \dagger$ & $101.5(14.2)$ & $100.6(14.2)$ & $102.4(14.2)$ & $100.2(15.0)$ & $103.0(13.1)$ \\
\hline FVC (\% pred)†, mean (SD) & $102.1(13.1)$ & $100.9(12.9)$ & $103.3(13.0)$ & $102.1(13.3)$ & $102.2(12.8)$ \\
\hline $\mathrm{FEV}_{1}: \mathrm{FVC}$, mean (SD) & $0.78(0.065)$ & $0.77(0.067)$ & $0.78(0.063)$ & $0.77(0.071)$ & $0.79(0.056)$ \\
\hline $\mathrm{CAL}_{\mathrm{GOLD}}, \mathrm{n}(\%)$ & $1461(9.7)$ & $814(11.2)$ & $647(8.2)$ & $1046(13.1)$ & $415(5.8)$ \\
\hline $\mathrm{CAL}_{\text {GOTHENBURG }}, \mathrm{n}(\%)$ & $1374(9.1)$ & $720(9.9)$ & $654(8.3)$ & $999(12.5)$ & $375(5.3)$ \\
\hline $\mathrm{CAL}_{\mathrm{GLI}}, \mathrm{n}(\%)$ & $778(5.1)$ & $378(5.2)$ & $400(5.1)$ & $591(7.4)$ & $187(2.6)$ \\
\hline
\end{tabular}

${ }^{*}$ Cough with phlegm, dyspnoea or wheezing.

†Reference values from Brisman et al. ${ }^{16}$

BMI, body mass index; CAL, chronic airflow limitation; FEV ${ }_{1}$, forced expiratory volume in 1 s; FVC, forced vital capacity; GLI, Global Lung Function Initiative; GOLD, Global Initiative for Chronic Obstructive Lung Disease; N.A., not applicable; \% pred, per cent predicted. 


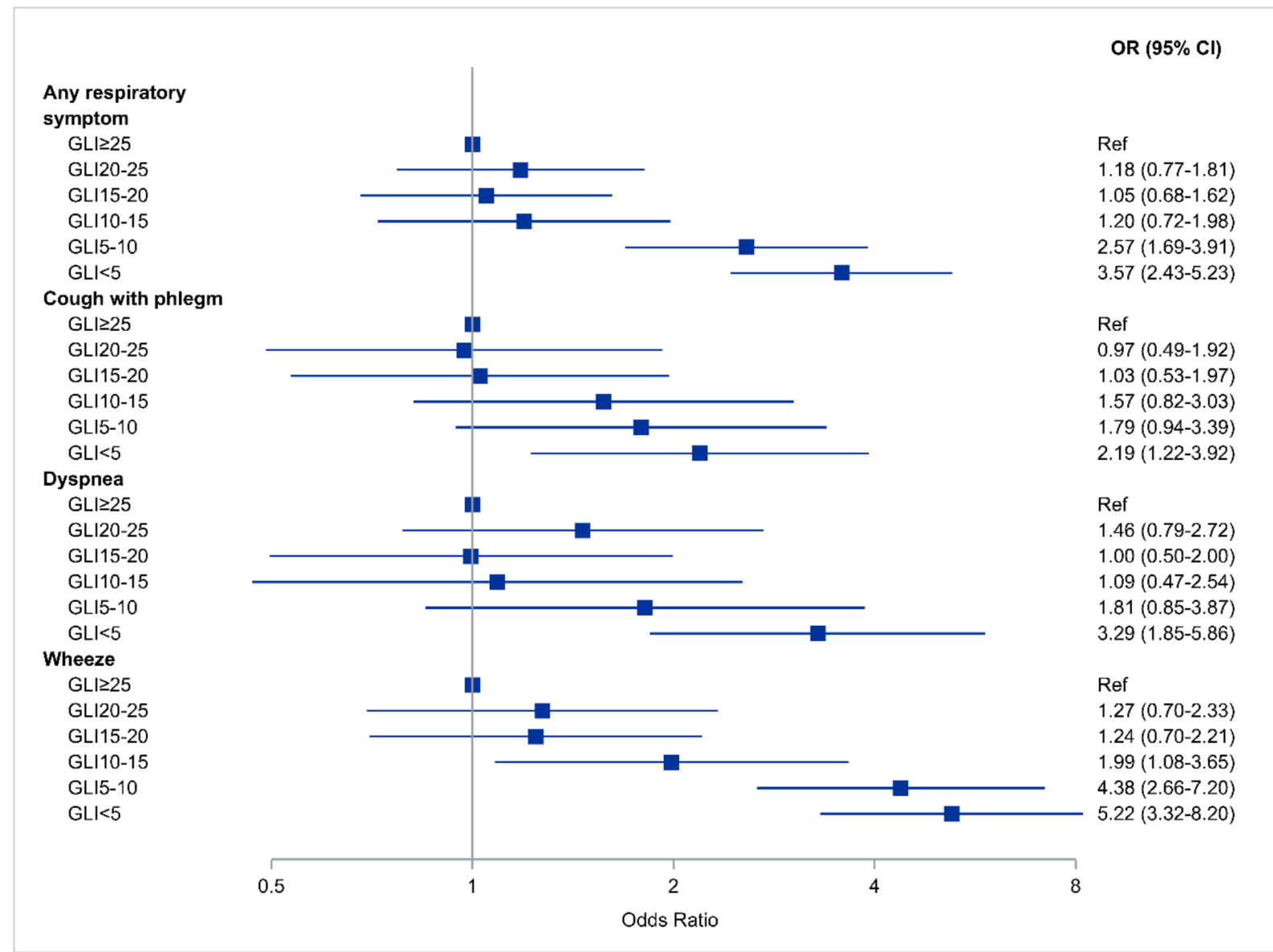

Figure 1 Forest plot of OR among never-smokers for any respiratory symptom, cough with phlegm, dyspnoea or wheezing according to GLI-based lower limit of normal for $\mathrm{FEV}_{1}$ :FVC ratio at successively higher percentiles. All models are adjusted

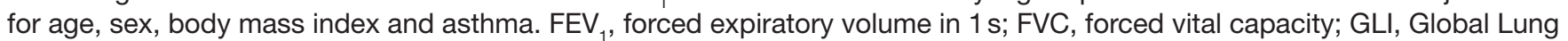
Function Initiative; ref, reference.

\section{Spirometry}

Dynamic spirometry including $\mathrm{FEV}_{1}$ and FVC was performed at least $15 \mathrm{~min}$ after inhalation of $400 \mu \mathrm{g}$ of salbutamol with the subject in a sitting position using a nose clip. ${ }^{15}$ In all measurements, a Jaeger MasterScreen PFT (Vyaire, Mettawa, Illinois, USA) was used. All procedures were performed according to the ATS/ERS standards. ${ }^{15}$ Based on the GLI equations, $z$-scores were calculated for $\mathrm{FEV}_{1}: \mathrm{FVC}, \mathrm{FEV}_{1}$ and FVC. ${ }^{10}$ A local reference material was used for calculation of per cent predicted of $\mathrm{FEV}_{1}$ and $\mathrm{FVC}$ and $\mathrm{LLN}_{5}$ for $\mathrm{FEV}_{1}: \mathrm{FVC}^{16}$

\section{Definitions}

- $\mathrm{CAL}_{\mathrm{GOLD}}$ was defined as $\mathrm{FEV}_{1}: \mathrm{FVC}<0.7$. $^{1}$

- $\mathrm{CAL}_{\mathrm{GOTHENBURG}}$ was defined as $\mathrm{FEV}_{1}: \mathrm{FVC}$ ratio below $\mathrm{LLN}_{5}$ using local reference equations. ${ }^{16}$

- $\mathrm{CAL}_{\mathrm{GLI}}$ was defined as $\mathrm{FEV}_{1}: \mathrm{FVC}$ below $\mathrm{GLI}_{5}$ applying the GLI equations. ${ }^{10}$

- Restrictive spirometric pattern $\left(\mathrm{RSP}_{\mathrm{GLI}}\right)$ was defined as $\mathrm{FEV}_{1}: \mathrm{FVC} \geq \mathrm{LLN}_{5}$ and $\mathrm{FVC}<\mathrm{LLN}_{5}$ based on the GLI equations. ${ }^{17}$
- Normal lung function $\left(\right.$ Normal $\left._{G \mathrm{II}}\right)$ was defined as $\mathrm{FEV}_{1}: \mathrm{FVC} \geq \mathrm{GLI}_{5}$ and $\mathrm{FVC} \geq \mathrm{GLI}_{5}$ using the GLI equations.

- Asthma was defined as 'physician-diagnosed asthma'. ${ }^{18}$

- Cough with phlegm was defined as cough with phlegm lasting for at least three consecutive months for at least 2 years.

- Dyspnoea was self-reported using the mMRC scale, and for this study dyspnoea was defined as mMRC $>1 .^{19-21}$

- Wheezing was defined as an affirmative answer to 'Do you have wheezing or whistling in your chest?'

- The primary outcome was a composite outcome any respiratory symptom, defined as having cough with phlegm, dyspnoea and/or wheezing. The different respiratory symptoms were also analysed separately, as secondary outcomes.

- Smoking history was categorised as current smokers, former smokers and never-smokers. Former smokers were defined as those who had smoked for at least 1 year but not during the last year. Ever-smokers included both current and former smokers. Packyears were calculated for all participants with a history 


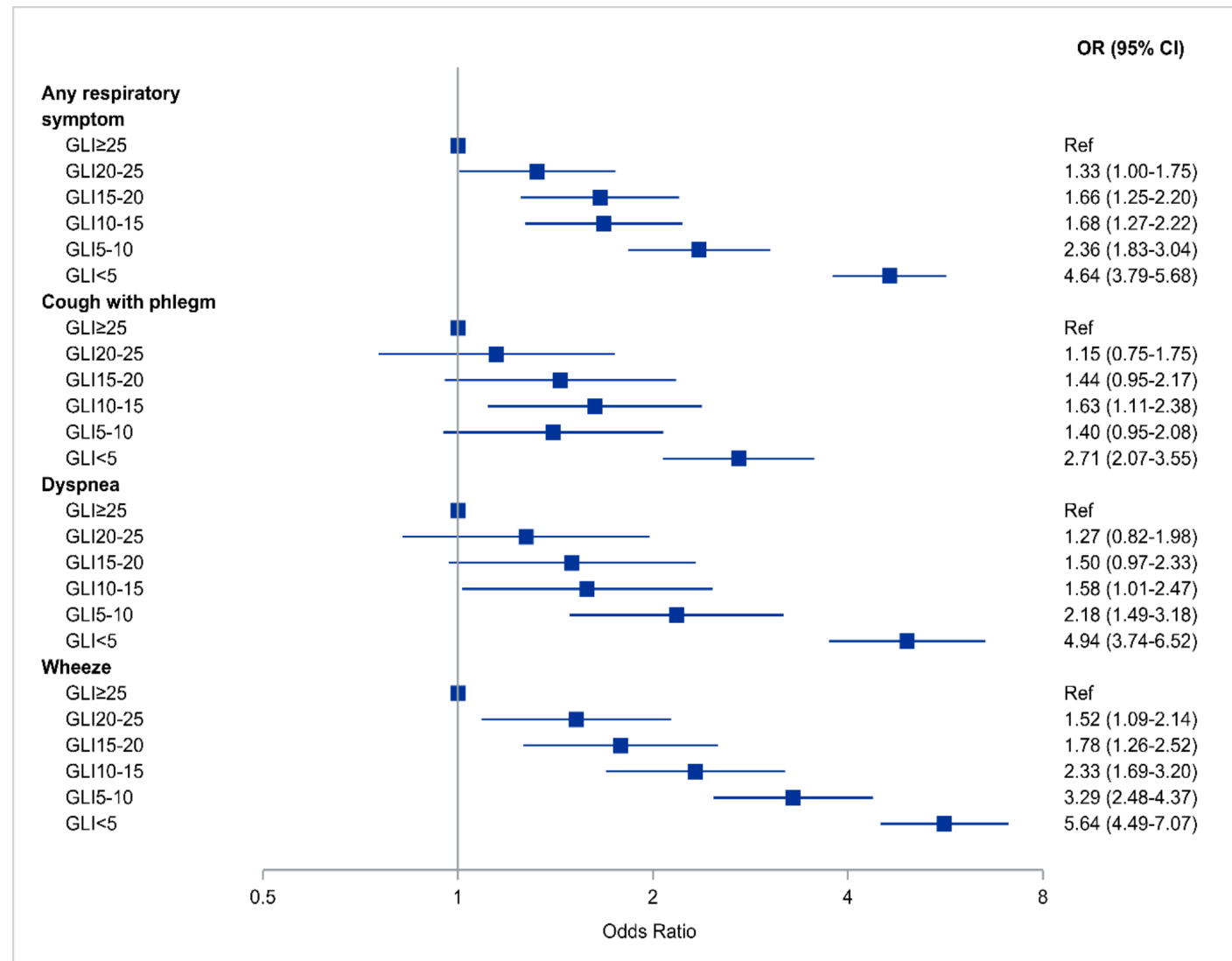

Figure 2 Forest plot of OR among ever-smokers for any respiratory symptom, cough with phlegm, dyspnoea or wheezing according to GLI-based lower limit of normal for $\mathrm{FEV}_{1}: \mathrm{FVC}$ ratio at successively higher percentiles. All models are adjusted for age, sex, body mass index, asthma, smoking and pack-years. FEV $_{1}$, forced expiratory volume in $1 \mathrm{~s}$; FVC, forced vital capacity; GLI, Global Lung Function Initiative; ref, reference.

of smoking. Never-smokers were defined as those who gave an affirmative answer to the item 'No, I have never smoked'.

- Body mass index (BMI) was defined as measured weight/height ${ }^{2}$.

\section{Patient and public involvement}

Patients and the public were not involved in the design, or conduct or reporting of the present research, the SCAPIS. The Swedish Heart and Lung Foundation is involved in the dissemination of the results.

\section{Statistics}

We calculated $z$-scores for the $\mathrm{FEV}_{1}: \mathrm{FVC}$ ratio using the GLI reference equations. ${ }^{10}$ We transformed the $z$-scores to quantiles of the normal distribution and defined groups using the 5th, 10th, 15th, 20th and 25th percentiles as cutoff points. For the sake of brevity, we here used the notation GLI with a number or range, for example, GLI $_{5-10}$ refers to individuals with $\mathrm{FEV}_{1}$ : $\mathrm{FVC}$ between the 5 th and 10th percentiles according to the GLI equations. We analysed the association between the GLI-defined strata and the primary outcome, any respiratory symptom, using OR estimated with multivariable logistic regression models among never-smokers, ever-smokers and all subjects. We also analysed the secondary outcomes, cough with phlegm, dyspnoea and wheezing. All models included age, sex, BMI, asthma, smoking and pack-years. The latter variables were not included in models for never-smokers. In one approach, we used individuals above the 25th percentile $\left(\mathrm{GLI}_{25}\right)$ as the reference group and presented the results in similarity with Vaz Fragoso et al. ${ }^{9}$ We used cubic restricted splines with four knots placed at the 5th, 35th, 65th and 95th percentiles for BMI and pack-years, respectively. ${ }^{22} \mathrm{We}$ also performed sensitivity analyses excluding all subjects with RSP, excluding all subjects with $\mathrm{FVC}<10$ th percentile and one model not adjusted for current smoking, that is, the model included only pack-years.

In an extended analysis, we treated the $z$-scores as a continuous variable using a spline with five knots placed at the observed quantiles $0.05,0.275,0.5,0.725$ and 0.95 . We used a $z$-score of 0 , that is, the 50th percentile $\left(\mathrm{GLI}_{50}\right)$, as the reference point for ORs and present the results as graphs with the $\mathrm{x}$-axis indicating percentiles.

All analyses were performed using SAS V.9.4M5. All results from the logistic regression models are expressed as OR with $95 \%$ CI. $P$ values $<0.05$ were considered significant.

\section{RESULTS}

Of the 15810 individuals originally included, 162 subjects were excluded due to incomplete spirometry 


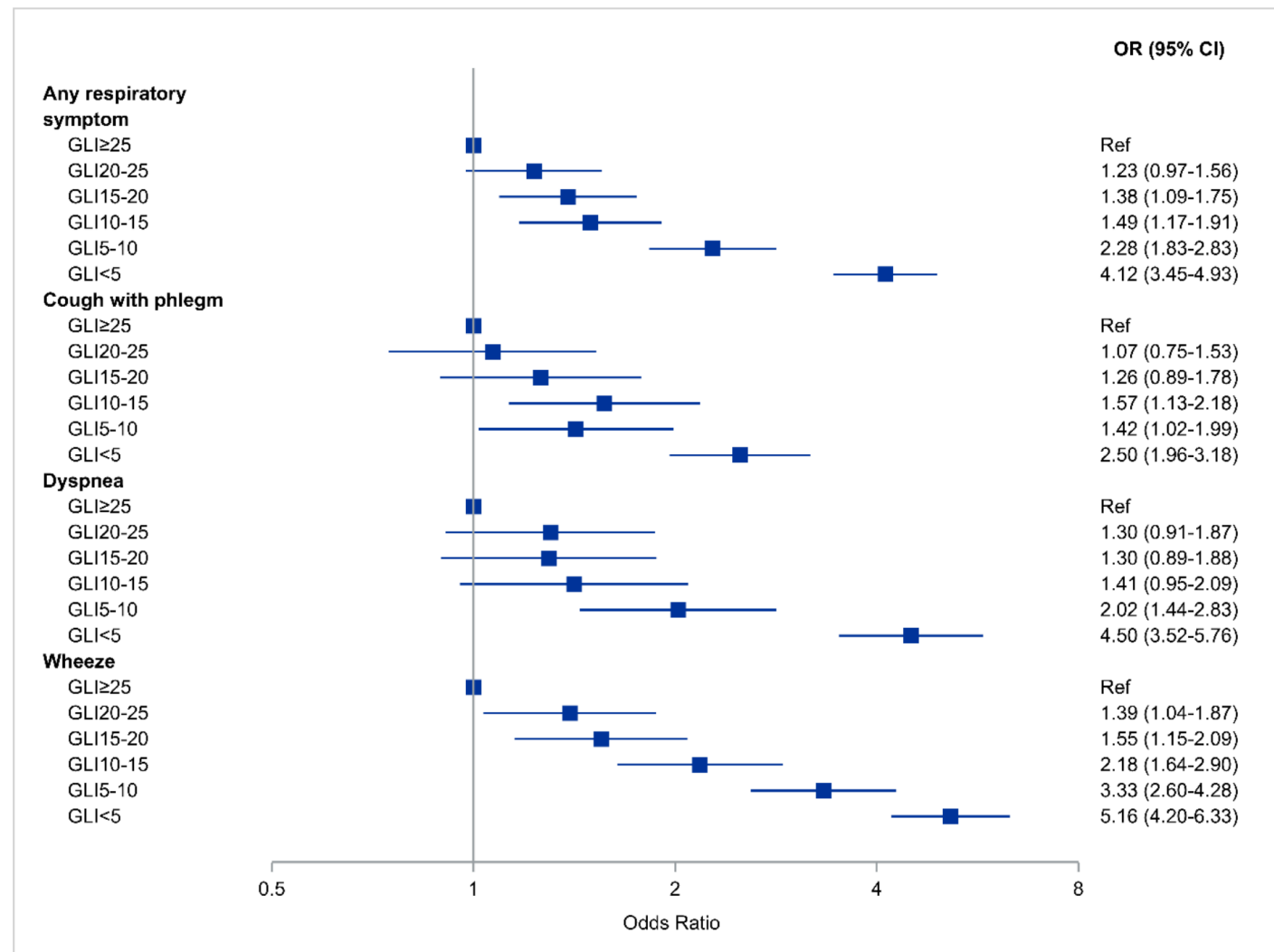

Figure 3 Forest plot of OR among all subjects for any respiratory symptom, cough with phlegm, dyspnoea or wheezing according to GLI-based lower limit of normal for $\mathrm{FEV}_{1}$ :FVC ratio at successively higher percentiles. All models are adjusted

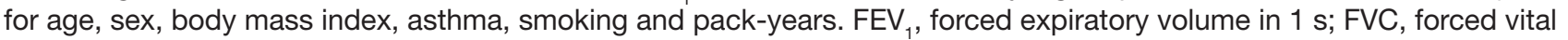
capacity; GLI, Global Lung Function Initiative; ref, reference.

data, 12 subjects because $\mathrm{FEV}_{1}>\mathrm{FVC}$ and 508 subjects due to incomplete data on smoking habits. The final study population of 15128 subjects is presented in table 1 . The mean age of participants was 57.5 years, $52.0 \%$ were women and $47.1 \%$ were never-smokers. The prevalence of any respiratory symptom was $13.3 \%$, among never-smokers $9.5 \%$ and among ever-smokers $16.8 \%$. The prevalence of $\mathrm{CAL}_{\text {GOLD }}(9.7 \%)$ and $\mathrm{CAL}_{\text {GOTHENBURG }}(9.1 \%)$ was significantly higher compared with $\mathrm{CAL}_{\mathrm{GLI}}$ prevalence $(5.1 \%)$. $\mathrm{RSP}_{\mathrm{GLI}}$ was found in 338 individuals $(2.2 \%)$.

Figures 1 and 2 show the forest plots of OR for any respiratory symptom for never-smokers and ever-smokers stratified according to the GLI strata for the $\mathrm{FEV}_{1}$ :FVC ratio, using $\mathrm{GLI}_{\geq 25}$ as the reference category. In neversmokers (figure 1), any respiratory symptom was significantly elevated in GLI $_{<5}$ (OR 3.57, 95\% CI 2.43 to 5.23) and in the stratum GLI $_{5-10}$ (OR 2.57, 95\% CI 1.69 to 3.91). Among ever-smokers (figure 2), any respiratory symptom was significantly increased in all five strata from GLI $\mathrm{L}_{<5}$ to GLI $_{20-25}$.

For the secondary outcomes, the separate symptoms, the results were somewhat different. Among neversmokers (figure 1), cough with phlegm and dyspnoea were only increased in the lowest strata $\left(\mathrm{GLI}_{<5}\right)$, but wheezing was increased up to $\mathrm{GLI}_{10-15}$. Among eversmokers (figure 2), cough with phlegm, dyspnoea and wheezing were elevated up to $\mathrm{GLI}_{10-15}$, and wheezing was increased even in the GLI GL-20 $_{15}$ strata.

In figure 3 the results are shown for all subjects, regardless of smoking habits. The odds of any respiratory symptom were elevated up to the GLI $_{15-20}$ strata, with less clear results for the separate symptoms of cough with phlegm, dyspnoea and wheezing.

A sensitivity analysis was performed excluding all individuals with RSP (data not presented). The results were almost similar for any respiratory symptom and the separate symptoms of cough with phlegm, dyspnoea and wheezing.

In an additional approach, we plotted the ORs for any respiratory symptom and the different symptoms of cough with phlegm, dyspnoea and wheezing in relation to GLI percentiles for never-smokers, ever-smokers and all subjects using $\mathrm{GLI}_{50}$ as the reference point (figures 4-6). The odds of any respiratory symptom continuously decreased with increasing GLI percentiles and flattened out towards unity at around $\mathrm{GLI}_{50}$. At higher percentiles the CIs were very wide. The results were similar for cough with phlegm, dyspnoea and wheezing. At higher GLI percentiles the odds of dyspnoea increased among neversmokers and among all subjects (figure 6).

In a sensitivity analysis, we excluded all individuals with FVC below the 10th percentile, that is, individuals with low FVC. This resulted in a curve that flattened out after 


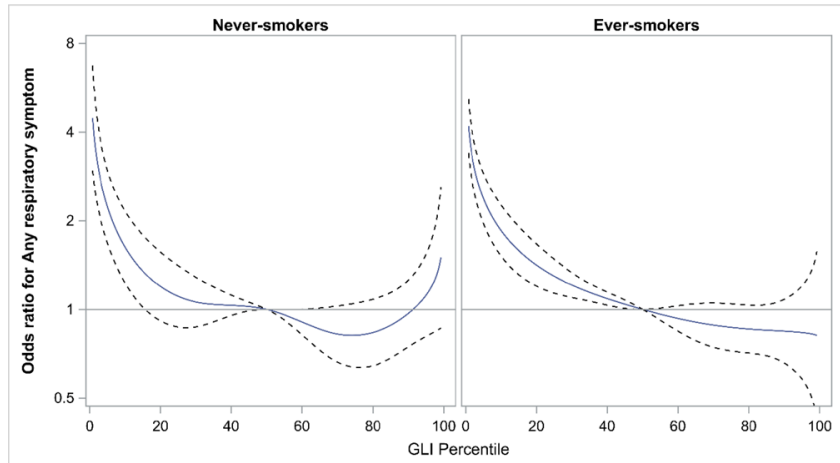

Figure 4 OR from multivariable logistic regression models for any respiratory symptom among never-smokers and ever-smokers in relation to $\mathrm{FEV}_{1}$ :FVC ratio at successively higher percentiles. We used the GLI reference equations with the 50th percentile as the reference point. All models are adjusted for age, sex, body mass index and asthma, and models for ever-smokers are also adjusted for smoking and pack-years. $\mathrm{FEV}_{1}$, forced expiratory volume in $1 \mathrm{~s}$; FVC, forced vital capacity; GLI, Global Lung Function Initiative.

GLI $_{50}$, similar to the other symptoms (data not shown). There was no obvious difference between never-smokers and ever-smokers regarding the shapes of the curves.

In an additional analysis we did not adjust for current smoking and the results were similar to previous analysis (see online supplementary file for details).

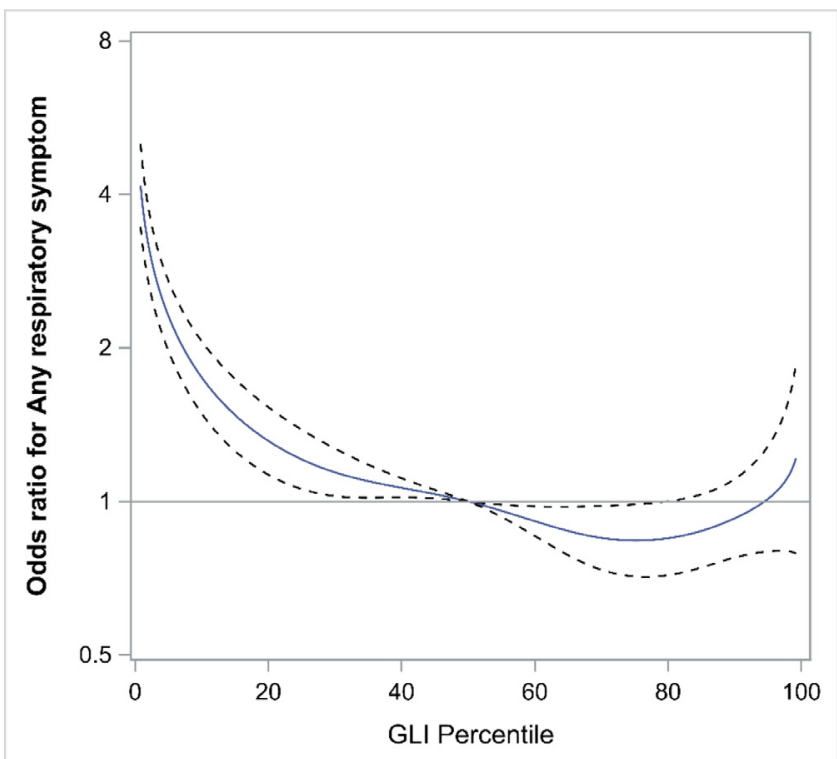

Figure 5 OR from multivariable logistic regression models for any respiratory symptom among all subjects in relation to $\mathrm{FEV}_{1}$ :FVC ratio at successively higher percentiles. We used the GLI reference equations with the 50th percentile as the reference point. All models are adjusted for age, sex, body mass index, asthma, smoking and pack-years. FEV forced expiratory volume in $1 \mathrm{~s}$; FVC, forced vital capacity; GLI, Global Lung Function Initiative.

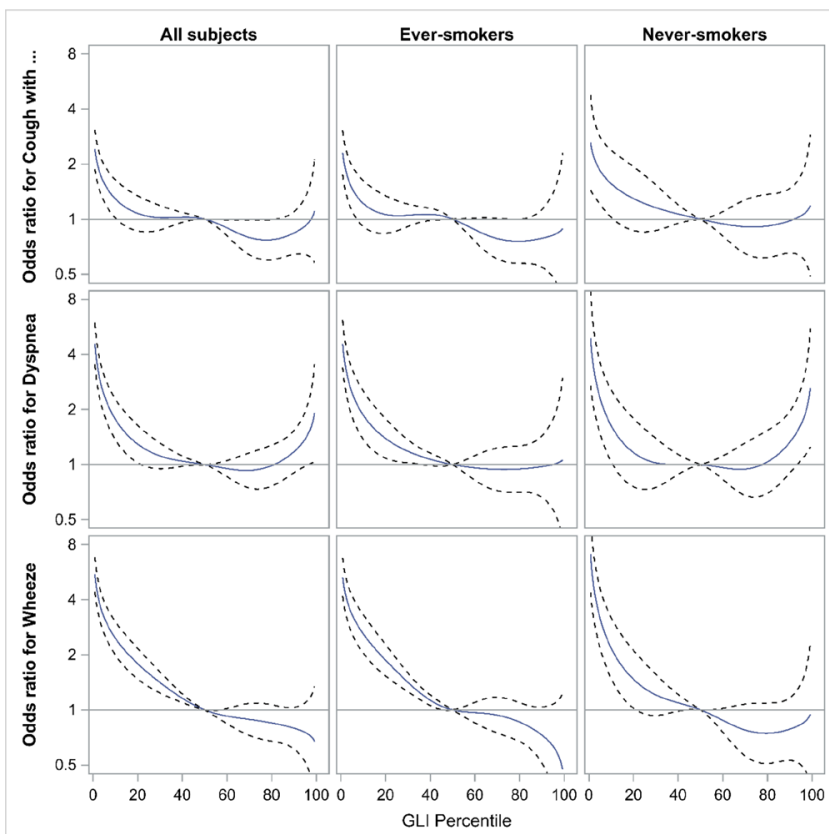

Figure 6 OR from multivariable logistic regression models for cough with phlegm, dyspnoea and wheezing among all subjects, never-smokers and ever-smokers in relation to the $\mathrm{FEV}_{1}$ :FVC ratio at successively higher percentiles. We used the GLI reference equations with the 50th percentile as the reference point. All models are adjusted for age, sex, body mass index and asthma, and models for ever-smokers are also adjusted for smoking and pack-years. $F_{1}$, forced expiratory volume in 1 s; FVC, forced vital capacity; GLI, Global Lung Function Initiative.

\section{DISCUSSION}

In the current paper, we describe substantial and important differences in the associations between CAL and respiratory symptoms depending on smoking history. Among never-smokers, we found support for a percentile cut-off of 10 rather than 5 when analysing increasing percentiles of $\mathrm{FEV}_{1}: \mathrm{FVC}$ in relation to the odds of COPDrelated respiratory symptoms. In ever-smokers, the results indicated even higher percentile cut-offs, showing a notable difference between never-smokers and eversmokers. Our results provide new data and may have important implications for how we in the future should define COPD. Important limitations of the study are the cross-sectional design and the lack of direct comparisons with the fixed ratio of $\mathrm{FEV}_{1}$ :FVC.

For decades, the diagnosis of COPD has been based on the presence of CAL (after bronchodilation). The use of $\mathrm{FEV}_{1}: \mathrm{FVC}<0.7$ has been advocated in previous and more recent guidelines, either using the fixed ratio or as LLN. ${ }^{23}$ It has also since long been recognised that individuals with $\mathrm{FEV}_{1}: \mathrm{FVC} \geq 0.7$ have increased prevalence of cough with phlegm and dyspnoea. This group was previously labelled as GOLD stage 0 , as they were regarded as a highrisk group among smokers to develop COPD. ${ }^{24}$ In recent GOLD recommendations, stage 0 is not included as there was insufficient evidence to conclude that this group 
had an increased risk to progress to COPD. ${ }^{25}$ However, there are a number of studies indicating that smokers with normal spirometry and respiratory symptoms may have evidence of airway disease and an increased risk for COPD. ${ }^{325-28}$ It has been proposed that these individuals may have early COPD yet without CAL. ${ }^{25}$

There is lack of data among never-smokers, but in the analyses of the Copenhagen General Population Study the presence of respiratory symptoms among neversmokers with normal lung function, defined as $\mathrm{FEV}_{1}: \mathrm{FVC}$ $\geq 0.7$, predicted COPD exacerbations and pneumonia hospitalisations in individuals with up to 15 years of follow-up data. ${ }^{4}$ Further, COPD in never-smokers was associated with an increased morbidity due to lung-related hospitalisations, despite a lower mortality compared with smokers with COPD. ${ }^{29}$ Our results add evidence to this discussion, as we show that never-smokers (and eversmokers) with $\mathrm{FEV}_{1}: \mathrm{FVC}>\mathrm{GLI}_{5}$ have increased odds of respiratory symptoms. We are fully aware that our results are based on cross-sectional data; however, our results still add evidence to the discussion whether the criteria for COPD or defining a population at risk for COPD should be revised, by for instance using a higher percentile instead of the fifth percentile.

We also analysed cough with phlegm, dyspnoea and wheezing and found that the odds of cough with phlegm and dyspnoea were increased up to GLI $\mathrm{F}_{5-10}$ among neversmokers; however, the CIs included unity. The odds of cough with phlegm and dyspnoea were clearly increased up to GLI $_{10-15}$ among ever-smokers. The odds of wheezing were increased even in the higher strata. The increased odds of wheezing, also at higher thresholds, probably reflect that wheezing also occurs among individuals with normal lung function, for instance in those with mild asthma. Given that we performed spirometry after bronchodilation, we minimised the risk of including individuals with asthma with reversible airflow limitation. Also, we adjusted in our models for self-reported asthma. Furthermore, chronic bronchitis may be associated with wheezing without necessarily being associated with significant CAL.

We extended the analysis and plotted the odds of any respiratory symptom, but also cough with phlegm, dyspnoea and wheezing and using GLI $_{50}$ as the anchor point. Here, we observed that the odds of respiratory symptoms continuously decreased the higher the GLI percentiles, and flattened out towards unity at a level close to $\mathrm{GLI}_{50}$. At higher levels the CIs were very wide. The main conclusion from this analysis is that whether increased odds in a stratum would be significant or not will depend on the sample size. Since all the information of the GLI $z$-score is used in these analyses, unlike the categorical analyses (in figures 1-3), a higher statistical power is expected.

Of note is that individuals with dyspnoea showed a different pattern. At high GLI percentiles, the odds increased, which means that subjects with high $\mathrm{FEV}_{1}: \mathrm{FVC}$ ratio, that is, individuals with low $\mathrm{FVC}$, also have increased prevalence of dyspnoea. In a sensitivity analysis, we excluded all individuals with FVC under the 10th percentile, which resulted in a curve that flattened out after GLI $_{50}$, similar to the other symptoms.

The use of the LMS method for assessing the percentiles has a strong methodological support. The main advantage is that it accounts for the age-related increase in airflow limitation, as well as the variability and normality deviations among the reference materials. ${ }^{8-10}$ Importantly, our analyses have a similar design as previous research, and our results among never-smokers are in line with previous results. ${ }^{9}$ However, when analysing the whole population and plotting the ORs, we obtained a smooth function without obvious thresholds. This fact lends further support to the idea that the decided level for an operational definition of COPD should be a decision based both on clinical and epidemiological evidence. ${ }^{30}$

We used a cross-sectional sample and based our analyses on the most important respiratory symptoms. Symptoms may be more sensitive to reporting bias compared with the more definitive outcome of mortality. On the other hand, respiratory symptoms reflect the individual's perceived health status, and respiratory symptoms are closely linked to exacerbations, disability and healthcare consumption. ${ }^{1531}$ Mortality is doubtless a clinically relevant outcome, and we have recently shown that there is no difference in cause-specific mortality for the GOLD and the ATS/ERS definitions. ${ }^{6}$ A similar analysis should be performed when it comes to different GLI thresholds. However, all-cause mortality has been shown to be increased using LLN $_{5}$ as a threshold with the LMS method. ${ }^{9}$

We are fully aware of the weaknesses of the present study. As previously commented, it is a cross-sectional study, which limits the validity of the conclusions. The study was performed within a narrow age range, namely 50-64 years, limiting the external validity to that age interval. Moreover, selection bias may be a problem, as the participation rate was around $50 \%$. In the current study population, having COPD and cardiovascular disease seems to have increased the participation rate. ${ }^{32}$ This may have increased the prevalence of individuals with symptoms and CAL in the examined population. The prevalence of ever-smokers, $53 \%$, is also slightly higher in our sample compared with other general population studies. ${ }^{33}$ The latter suggests that there might be some selection bias in relation to smoking habits. However, our main results are based on analyses of never-smokers, a group with lesser risk for COPD and cardiovascular diseases. Hence, we conclude that despite the possibility of a selection bias in our study, we suggest that the threshold values obtained among never-smokers would only have been marginally affected.

Our study also has evident strengths. We used a large general population-based sample comprising eversmokers as well as lifelong never-smokers. This is an advantage as there is a need for data from never-smoking general population-based samples. Furthermore, spirometry was performed after bronchodilator administration 
to assess true CAL. Importantly, when comparing the obtained prevalence figures with results from other studies, it should be considered that many of them used prebronchodilator values, and prebronchodilator values may misclassify and overestimate the prevalence of $\mathrm{CAL}_{\mathrm{GOLD}}{ }^{34}$

In conclusion, a substantial and clinically important difference was found between never-smokers and eversmokers with regard to COPD-related respiratory symptoms. When using $\mathrm{GLI}_{\geq 25}$ as the reference category, our results seem to support a percentile cut-off of 10 for percentiles of $\mathrm{FEV}_{1}: \mathrm{FVC}$ among never-smokers and an even higher percentile for ever-smokers. Of importance, the relation between different percentiles of $\mathrm{FEV}_{1}: \mathrm{FVC}$ and the different symptoms was a smooth function without obvious thresholds.

\section{Author affiliations}

${ }^{1}$ Occupational and Environmental Medicine/School of Public Health and Community Medicine, University of Gothenburg, Goteborg, Sweden ${ }^{2}$ Occupational and Environmental Medicine, Sahlgrenska University Hospital, Gothenburg, Sweden

${ }^{3}$ Public Health and Clinical Medicine, Division of Medicine, Umeå University, Umeå, Sweden

${ }^{4}$ COPD center, Sahlgrenska University Hospital, Gothenburg, Sweden

${ }^{5}$ Institute of Medicine, University of Gothenburg, Gothenburg, Sweden

${ }^{6}$ Public Health and Clinical Medicine, Umeå University, Umeå, Sweden

${ }^{7}$ Department of Molecular and Clinical Medicine, Sahlgrenska Academy, University of Gothenburg, Gothenburg, Sweden

${ }^{8}$ Molecular Medicine and Surgery, Karolinska Institutet, Stockholm, Sweden

${ }^{9}$ Center of Medical Image Science and Visualization, Linköping University, Linköping, Sweden

${ }^{10}$ Clinical Physiology, Linköping University, Linköping, Sweden

${ }^{11}$ Department of Clinical Physiology, Karolinska University Hospital,

Stockholm, Sweden

${ }^{12}$ Clinical Sciences, Lund University, Lund, Sweden

${ }^{13}$ Department of Internal Medicine, Skåne University Hospital, Malmö, Sweden

${ }^{14}$ Department of Medical Sciences: Respiratory Medicine, Uppsala University, Uppsala, Sweden

${ }^{15}$ Unit for Lung and Airway Research, Institute of Environmental Medicine, Karolinska Institutet and Karolinska University Hospital, Stockholm, Sweden

${ }^{16}$ Department of Medical Sciences Clinical Physiology, Uppsala University, Uppsala, Sweden

${ }^{17}$ Department of Respiratory Medicine, Department of Medical and Health Sciences, Linköping University, Linköping, Sweden

${ }^{18}$ Department of Immunology, Genetics and Pathology, Uppsala University, Uppsala, Sweden

${ }^{19}$ Department of Respiratory Medicine and Allergology, Skåne University Hospital, Lund University, Malmö, Sweden

${ }^{20}$ Department of Radiology, Sahlgrenska University Hospital, Gothenburg, Sweden

${ }^{21}$ Department of Medical and Health Sciences, Linköping University, Linköping, Sweden

${ }^{22}$ Clinical Physiology, Skåne University Hospital, Lund University, Malmö, Sweden

${ }^{23}$ Department of Medicine, Respiratory Medicine Unit, Center for Molecular Medicine, Karolinska Institutet, Stockholm, Sweden

${ }^{24}$ Department of Respiratory Medicine and Allergy, Karolinska University Hospital, Solna, Sweden

Contributors The following are members of SCAPIS National Steering Committee and therefore responsible for design, funding, planning and execution of SCAPIS: $A B, G B, J E, C M S, K T$, CJÖ and EL. Responsible for the conception and design of the analyses included in the specific manuscript and first draft: KT, LS, AL and AM. Data collection: AA, AFB, KC, ME, VH, CJ, ÅJ, DK, AL, HLP, CMS, JES, HAT, JV and PW. Statistical analysis: LS. All authors were involved in the planning and data interpretation and revision of manuscript drafts for important intellectual content, and approval of the version to be submitted.

Funding The main funding body of the Swedish CArdioPulmonary biolmage Study (SCAPIS) is the Swedish Heart and Lung Foundation. The study is also funded by the Knut and Alice Wallenberg Foundation, the Swedish Research Council and VINNOVA (Sweden's innovation agency), the University of Gothenburg and Sahlgrenska University Hospital, Karolinska Institutet and Karolinska University Hospital, Linköping University and University Hospital, Lund University and Skåne University Hospital, Umeå University and University Hospital, and Uppsala University and University Hospital. There was also individual research support from the Swedish state under the agreement between the Swedish government and the county councils, the ALF agreement.

Competing interests AA reports personal fees from Novartis and AstraZeneca, outside this work. AL reports personal fees from Boehringer Ingelheim, AstraZeneca, Novartis and Active Care, outside the submitted work. JV reports personal fees from Boehringer Ingelheim, outside the submitted work. PW reports personal fees from AstraZeneca and Chiesi Pharmaceuticals, outside the submitted work. CMS reports personal fees from Boehringer Ingelheim, GlaxoSmithKline, Novartis, AstraZeneca, Roche and Genzyme, outside the submitted work. PW has a patent device and method for pulmonary capacity measurements issued. MS reports personal fees from AstraZeneca, outside the submitted work.

Patient consent for publication Not required.

Ethics approval The study was approved by the Regional Ethical Review Board at Umeå University (nr: 2010- 228-31 M), and all participants provided written informed consent.

Provenance and peer review Not commissioned; externally peer reviewed.

Data availability statement Data are available upon reasonable request. A prerequisite is an approval from a Swedish ethical board.

Open access This is an open access article distributed in accordance with the Creative Commons Attribution Non Commercial (CC BY-NC 4.0) license, which permits others to distribute, remix, adapt, build upon this work non-commercially, and license their derivative works on different terms, provided the original work is properly cited, appropriate credit is given, any changes made indicated, and the use is non-commercial. See: http://creativecommons.org/licenses/by-nc/4.0/.

ORCID ID

Hans Lennart Persson http://orcid.org/0000-0002-5700-7284

\section{REFERENCES}

1 Vogelmeier CF, Criner GJ, Martinez FJ, et al. Global strategy for the diagnosis, management, and prevention of chronic obstructive lung disease 2017 report. gold executive summary. Am J Respir Crit Care Med 2017;195:557-82.

2 Singh D, Agusti A, Anzueto A, et al. Global strategy for the diagnosis, management, and prevention of chronic obstructive lung disease: the gold science Committee report 2019. Eur Respir J 2019;53:1900164.

3 Woodruff PG, Barr RG, Bleecker E, et al. Clinical significance of symptoms in smokers with preserved pulmonary function. $N$ Engl $J$ Med 2016;374:1811-21.

4 Çolak Y, Nordestgaard BG, Vestbo J, et al. Prognostic significance of chronic respiratory symptoms in individuals with normal spirometry. Eur Respir J 2019:54:1900734.

5 Lamprecht B, McBurnie MA, Vollmer WM, et al. Copd in never smokers: results from the population-based burden of obstructive lung disease study. Chest 2011;139:752-63.

6 Torén K, Andersson M, Olin A-C, et al. Airflow limitation classified with the fixed ratio or the lower limit of normal and cause-specific mortality - A prospective study. Respir Med 2018;144:36-41.

7 Brusasco V. Spirometric definition of COPD: exercise in futility or factual debate? Thorax 2012;67:569-70.

8 Pellegrino R, Viegi G, Brusasco V, et al. Interpretative strategies for lung function tests. Eur Respir J 2005;26:948-68.

9 Vaz Fragoso CA, Concato J, McAvay G, et al. The ratio of FEV1 to FVC as a basis for establishing chronic obstructive pulmonary disease. Am J Respir Crit Care Med 2010;181:446-51.

10 Quanjer PH, Stanojevic S, Cole TJ, et al. Multi-Ethnic reference values for spirometry for the 3-95-yr age range: the global lung function 2012 equations. Eur Respir J 2012;40:1324-43.

11 Vaz Fragoso CA, Concato J, McAvay G, et al. Defining chronic obstructive pulmonary disease in older persons. Respir Med 2009;103:1468-76.

12 Gross NJ. Chronic obstructive pulmonary disease outcome measurements. Proc Am Thorac Soc 2005;2:267-71. 
13 Bergström G, Berglund G, Blomberg A, et al. The Swedish cardiopulmonary Biolmage study: objectives and design. J Intern Med 2015;278:645-59.

14 Torén K, Olin A-C, Lindberg A, et al. Vital capacity and COPD: the Swedish cardiopulmonary biolmage study (SCAPIS). Int J Chron Obstruct Pulmon Dis 2016:11:927-33.

15 Miller MR, Hankinson J, Brusasco V, et al. ATS/ERS Task force standardisation of spirometry. Eur Respir J 2005;26:319-38.

16 Brisman J, Kim J-L, Olin A-C, et al. Spirometric reference equations for Swedish adults. Clin Physiol Funct Imaging 2017;37:640-5.

17 Torén K, Schiöler L, Brisman J, et al. Restrictive spirometric pattern and true pulmonary restriction in a general population sample aged 50 - 64 years. BMC Pulm Med 2020;20:55.

18 Torén $\mathrm{K}$, Palmqvist $\mathrm{M}$, Löwhagen $\mathrm{O}$, et al. Accuracy of self-reported year of asthma-onset. J Clin Epidemiol 2006;59:90-3.

19 Bestall JC, Paul EA, Garrod R, et al. Usefulness of the medical Research Council (MRC) dyspnoea scale as a measure of disability in patients with chronic obstructive pulmonary disease. Thorax 1999;54:581-6.

20 Ekström MP, Blomberg A, Bergström G, et al. The association of body mass index, weight gain and central obesity with activityrelated breathlessness: the Swedish cardiopulmonary Bioimage study. Thorax 2019;74:958-64.

21 Parshall MB, Schwartzstein RM, Adams L, et al. American thoracic Society Committee on D. an official American thoracic Society statement: update on the mechanisms, assessment, and management of dyspnea. Am J Respir Crit Care Med 2012;185:435-52.

22 Harrell F. Regression modeling strategies with applications to linear models, logistic and ordinal regression, and survival analysis. 2nd Edition. New York: Springer, 2015.

23 Barnes PJ, Vestbo J, Calverley PM. The Pressing Need to Redefine "COPD". Chronic Obstr Pulm Dis 2019;6:380-3.

24 Pauwels RA, Buist AS, Calverley PM, et al. Global strategy for the diagnosis, management, and prevention of chronic obstructive pulmonary disease. NHLBI/WHO global initiative for chronic obstructive lung disease (gold) workshop summary. Am J Respir Crit Care Med 2001;163:1256-76.

25 Rodriguez-Roasin R, Han MK, Vestbo J, et al. Chronic respiratory symptoms with normal spirometry. A reliable clinical entity? Am J Respir Crit Care Med 2017;195:17-22.

26 Tan WC, Bourbeau J, Hernandez P, et al. Exacerbation-like respiratory symptoms in individuals without chronic obstructive pulmonary disease: results from a population-based study. Thorax 2014:69:709-17.

27 Bhatt SP, Balte PP, Schwartz JE, et al. Discriminative accuracy of FEV : FVC thresholds for COPD-related hospitalization and mortality. JAMA 2019;321:2438-47.

28 Lowe KE, Regan EA, Anzueto A, et al. COPDGene ${ }^{\circledR}$ 2019: Redefining the Diagnosis of Chronic Obstructive Pulmonary Disease. Chronic Obstr Pulm Dis 2019;6:384-99.

29 Thomsen M, Nordestgaard BG, Vestbo J, et al. Characteristics and outcomes of chronic obstructive pulmonary disease in never smokers in Denmark: a prospective population study. Lancet Respir Med 2013;1:543-50.

30 Feinstein AR. The inadequacy of binary models for the clinical reality of three-zone diagnostic decisions. J Clin Epidemiol 1990;43:109-13.

31 Sundh J, Janson C, Lisspers K, et al. The dyspnoea, obstruction, smoking, exacerbation (dose) index is predictive of mortality in COPD. Prim Care Respir J 2012;21:295-301.

32 Björk J, Strömberg U, Rosengren A, et al. Predicting participation in the population-based Swedish cardiopulmonary bio-image study (SCAPIS) using register data. Scand J Public Health 2017;45:45-9.

33 Olin A-C, Rosengren A, Thelle DS, et al. Height, age, and atopy are associated with fraction of exhaled nitric oxide in a large adult general population sample. Chest 2006:130:1319-25.

34 Johannessen A, Omenaas ER, Bakke PS, et al. Implications of reversibility testing on prevalence and risk factors for chronic obstructive pulmonary disease: a community study. Thorax 2005;60:842-7. 